\title{
An Isothiourea-catalyzed Asymmetric [2,3]-Rearrangement of Allylic Ammonium Ylides
}

\author{
Thomas H. West, David S. B. Daniels, Alexandra M. Z. Slawin, and Andrew D. Smith* \\ EaStCHEM, School of Chemistry, University of St Andrews, North Haugh, St Andrews, KY16 9ST, UK
}

\section{Supporting Information Placeholder}

\begin{abstract}
Benzotetramisole promotes the catalytic asymmetric [2,3]-rearrangement of allylic quaternary ammonium salts (either isolated or prepared in situ from $p$-nitrophenyl bromoacetate and the corresponding allylic amine), generating syn- $\alpha$-amino acid derivatives with excellent diastereo- and enantioselectivity (up to $>95: 5 \mathrm{dr}$; up to $>99 \%$ ee).
\end{abstract}

The [2,3]-rearrangement ${ }^{1}$ of glycine-derived allylic ammonium ylides is widely recognized as a versatile process for the synthesis of stereodefined unnatural $\alpha$ amino acid derivatives containing multiple stereocentres. ${ }^{2}$ Current limitations of this processes include the difficulty associated with the generation and isolation of the reactive ammonium salts, ${ }^{3}$ alongside the development of catalytic asymmetric methods for inducing enantiocontrol. ${ }^{4}$ Recent work by Tambar and Sohelie has elegantly utilized Pd-catalyzed allylic substitution to facilitate tandem ammonium ylide generation and [2,3]rearrangement, generating racemic anti-configured products 3 with high diastereoselectivity (Scheme 1, eq 1). ${ }^{5}$ While asymmetric [2,3]-rearrangements of allylic ammoniums can be induced by chiral auxiliary control as demonstrated by Sweeney and co-workers, ${ }^{4 a}$ Somfai et al. have applied stoichiometric asymmetric Lewis acids to promote the enantioselective rearrangement of allylic amines 5 (Scheme 2, eq 2). ${ }^{4 \mathrm{~b}, 6}$ Within the last fifteen years, advances in asymmetric organocatalysis ${ }^{7}$ have been applied to asymmetric [3,3]-sigmatropic rearrangements. ${ }^{8} \quad$ However, organocatalytic [2,3]sigmatropic rearrangements are an underexplored concept, with the secondary amine catalyzed [2,3]-Wittig rearrangement developed by Gaunt et al. representing the current state-of-the-art within this area. ${ }^{9}$ Given our interest in Lewis base promoted organocatalytic processes, ${ }^{10}$ in this manuscript we show that substoichiometric isothioureas ${ }^{11}$ promote the asymmetric [2,3]-rearrangement of ylides $\mathbf{1 0}$ derived from isolable or in situ generated allylic ammonium salts 9, forming stereodefined $\alpha$-amino acid derivatives $\mathbf{1 1}$ with excellent syn-diastereocontrol and enantiocontrol (up to $>95: 5 \mathrm{dr}$ and $99 \%$ ee) (Scheme 1, eq 3).

Scheme 1: [2,3]-Rearrangements of Allylic Ammonium Ylides
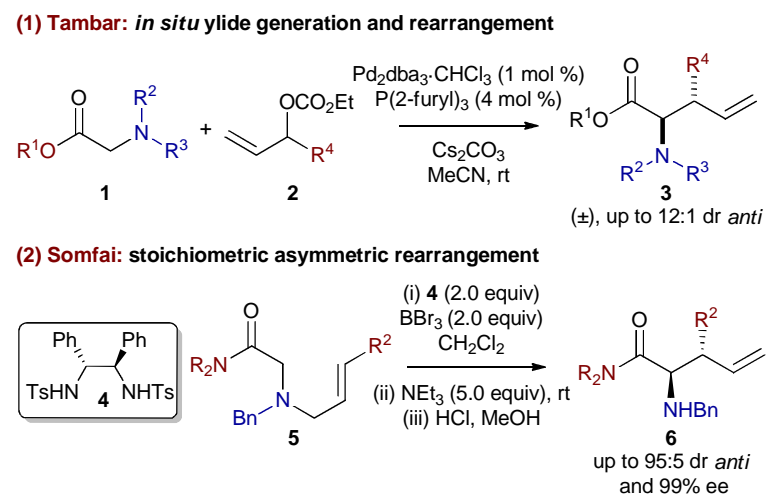

(3) This work: catalytic asymmetric rearrangement
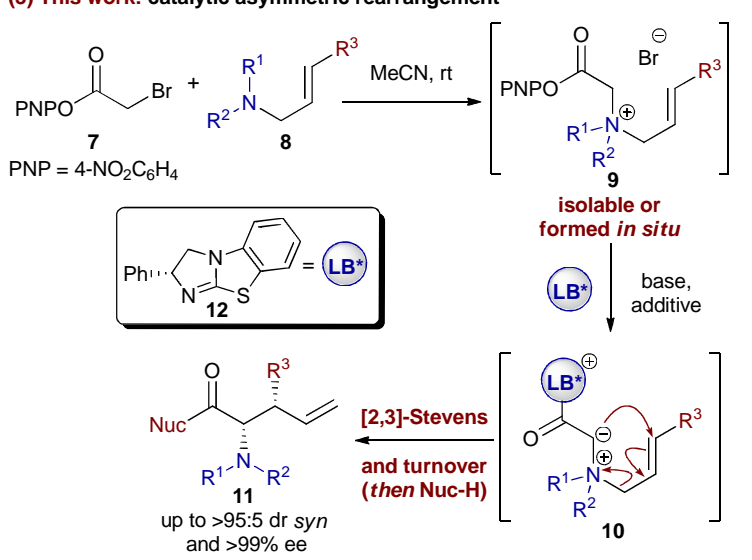

Proof of concept studies focused upon asymmetric isothiourea-promoted [2,3]-rearrangement of pre-formed allylic ammonium salt $\mathbf{1 3}$ bearing an activated $p$ nitrophenyl ester (Table 1). ${ }^{12,13}$ Treatment of ammonium salt 13 with (-)-tetramisole $\cdot \mathrm{HCl} 15(20 \mathrm{~mol} \%)$ and $i \mathrm{Pr}_{2} \mathrm{NH}$ at $\mathrm{rt}$ led to [2,3]-Stevens rearrangement, with subsequent nucleophilic quench with benzylamine giving amide 14 in 89:11 dr and promising 81\% ee (entry 1). ${ }^{14}$ Further optimization showed that addition of HOBt (20 $\mathrm{mol} \%$ ) as a co-catalyst led to improved diastereoand enantiocontrol (entry 2). ${ }^{15}$ Alternative organic bases 
such as $i \mathrm{Pr}_{2} \mathrm{NEt}$ or $\mathrm{NEt}_{3}$ could also be used without affecting the $\mathrm{dr}$ or ee, although $N$-methylmorpholine gave reduced diastereocontrol. ${ }^{16}$ Lowering the reaction temperature to $-20{ }^{\circ} \mathrm{C}$ gave increased product ee, whilst catalyst variation showed that (+)-benzotetramisole (BTM) was optimal, giving $\mathbf{1 4}$ in $76 \%$ yield, $>95: 5 \mathrm{dr}$ and $99 \%$ ee (entries 3-7). The additive HOBt is essential to achieve excellent stereocontrol when using BTM at $-20{ }^{\circ} \mathrm{C}$ (entries 5 and 6), whilst reduced catalyst loadings gave lower, but still acceptable, asymmetric induction (entries 9-10).

\section{Table 1: Optimization of Reaction Conditions}
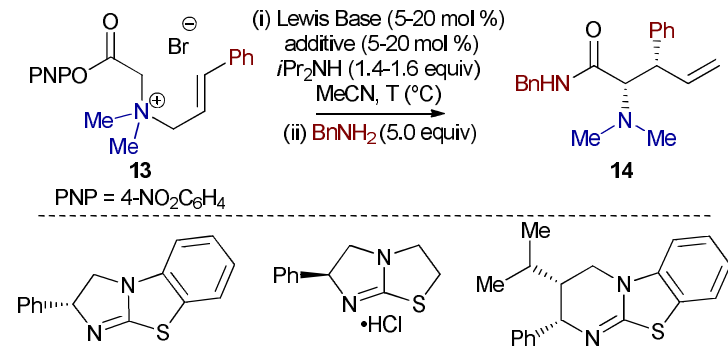

(+)-benzotetramisole 12 (-)-tetramisole $\cdot \mathrm{HCl} 15$

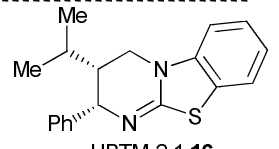

HBTM-2.1 16

\begin{tabular}{ccccccc}
\hline Entry & LB $^{\mathrm{a}}$ & additive $^{\mathrm{a}}$ & $\mathrm{T}\left({ }^{\circ} \mathrm{C}\right)$ & ${\text { Yield }(\%)^{b, c}}^{b}$ & $\mathrm{dr}^{d}$ & $\mathrm{ee}^{e}$ \\
\hline 1 & $\mathbf{1 5}$ & -- & $\mathrm{rt}$ & $(83)^{c}$ & $89: 11$ & $81($ ent $)$ \\
2 & $\mathbf{1 5}$ & $\mathrm{HOBt}$ & $\mathrm{rt}$ & 68 & $93: 7$ & $84($ ent $)$ \\
3 & $\mathbf{1 5}$ & $\mathrm{HOBt}$ & 0 to $\mathrm{rt}$ & 88 & $92: 8$ & $89($ ent $)$ \\
4 & $\mathbf{1 2}$ & $\mathrm{HOBt}$ & -20 & 65 & $91: 9$ & $93($ ent $)$ \\
5 & $\mathbf{1 2}$ & -- & -20 & 61 & $92: 8$ & 95 \\
6 & $\mathbf{1 2}$ & $\mathbf{H O B t}$ & $-\mathbf{2 0}$ & $\mathbf{7 6}$ & $>\mathbf{9 5 : 5}$ & $\mathbf{9 9}$ \\
7 & $\mathbf{1 6}$ & $\mathrm{HOBt}$ & -20 & $(33)^{c}$ & $62: 38$ & $\mathrm{ND}$ \\
8 & $\mathbf{1 2}$ & $\mathrm{HOAt}$ & -20 & 49 & $90: 10$ & 98 \\
9 & $\mathbf{1 2}^{f}$ & $\mathrm{HOBt}^{f}$ & -20 & 62 & $88: 12$ & 96 \\
10 & $\mathbf{1 2}^{g}$ & $\mathrm{HOBt}^{g}$ & -20 & $41^{h}$ & $79: 21$ & 92 \\
\hline
\end{tabular}

Reactions performed on $0.24 \mathrm{mmol} \mathrm{scale}{ }^{a} 20 \mathrm{~mol} \%$ unless stated. ${ }^{b}$ Isolated yield after chromatographic purification of $>95: 5 \mathrm{dr}$. ${ }^{c}$ Yield in parentheses determined by ${ }^{1} \mathrm{H}$ NMR in comparison to internal standard (4-nitrotoluene). ${ }^{d}$ Determined by ${ }^{1} \mathrm{H}$ NMR analysis of crude material. ${ }^{e}$ Determined by Chiral HPLC analysis. ${ }^{f} 10$ mol\%. ${ }^{g} 5 \mathrm{~mol} \%$. ${ }^{h}$ Isolated as a 84:16 mixture of diastereomers.

With an optimized protocol identified, the scope of this process was initially examined through sequential variation of the nucleophile (Table 2). Using ammonium salt 13, N,O-dimethylhydroxylamine, pyrrolidine, methoxide, or $\mathrm{LiAlH}_{4}$ could be used to generate functionalized amino carbonyl and alcohol compounds 17-20 in good yields, high $\mathrm{dr}$ and ee. This process is readily scalable, with $1.95 \mathrm{~g}$ of amino ester 19 (86\% yield, $95: 5 \mathrm{dr}, 95 \%$ ee) generated from $9.6 \mathrm{mmol}$ of salt $\mathbf{1 3}$. Various $\mathrm{N}$ substituents encompassing simple and functionalized piperidines, morpholine and $N$-Boc-piperazine motifs are readily accommodated, giving functionalized amino amides (21-25) in excellent yield (80-89\%), $\mathrm{dr}$ and ee (up to >95:5 dr and >99\% ee). Variation of the allylic $C$ (3)-aryl substituent within the salt showed that both electron-donating and withdrawing 4-substituents are well tolerated (26-28). 2-Substitution of the aryl ring can also be incorporated, albeit in only modest isolated yields but high dr and ee (29 and $\mathbf{3 0}$ ).
Table 2: Scope of Isolable Ammonium Salts
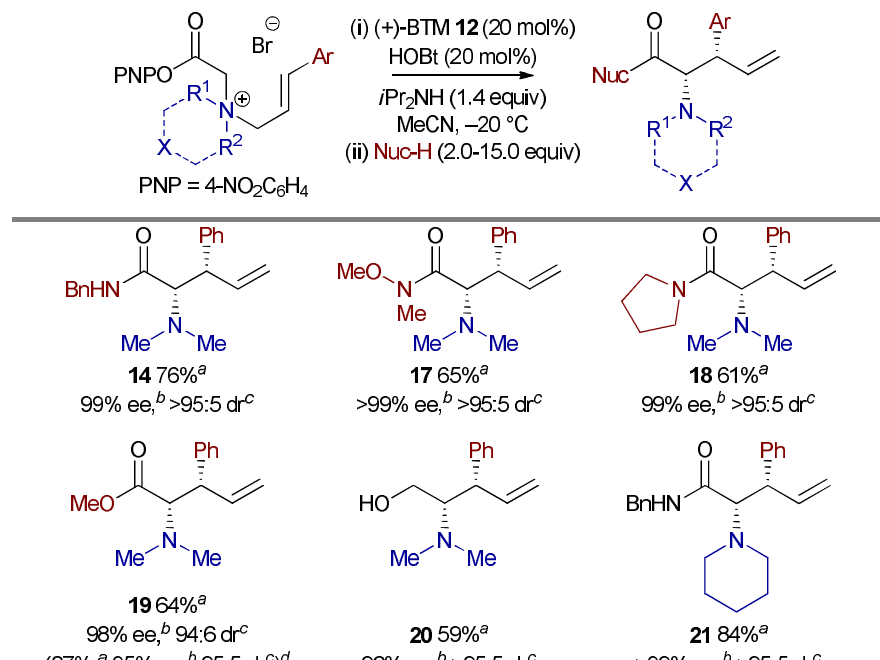
$\left(87 \%,{ }^{a} 95 \% \text { ee, }{ }^{b} 95: 5 \mathrm{dr}^{c}\right)^{d}$

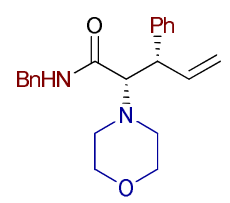

$2282 \%^{a}$
$86 \% e^{b} 946 \mathrm{dr}^{c}$
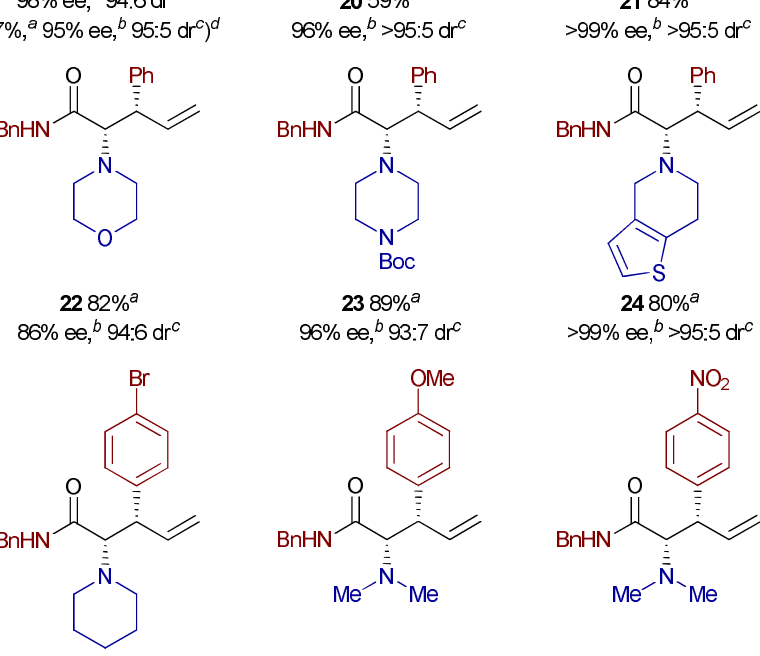

$2587 \%^{a}$

$98 \% e^{b}>95: 5 d^{c}$

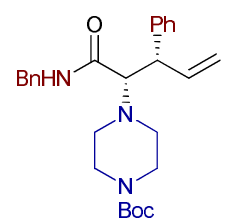

$2389 \%^{a}$

$96 \% \Subset,{ }^{b} 93: 7 \mathrm{dr} c$

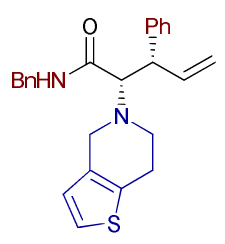

$2480 \%^{a}$
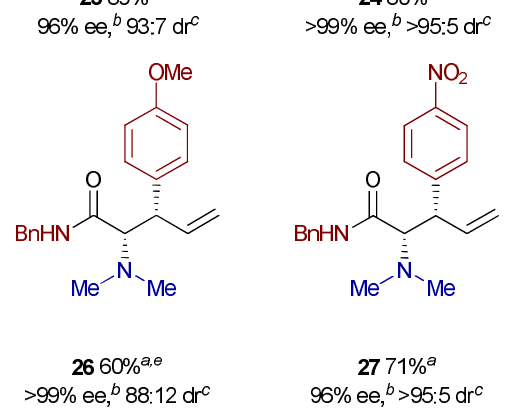

$2771 \%^{a}$
$96 \%$ ee ${ }^{b}>95: 5 \mathrm{dr}^{c}$

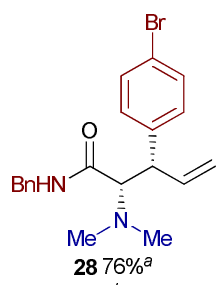

$>99 \% €{ }^{b} 95: 5 d^{c}$
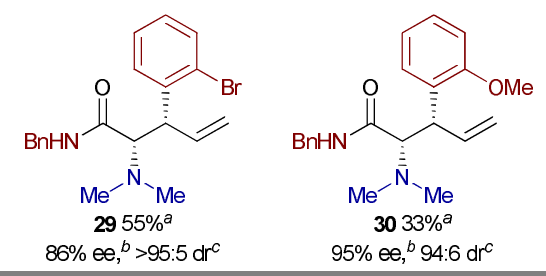

${ }^{a}$ Isolated yield after chromatographic purification of $>95: 5 \mathrm{dr}$ ${ }^{b}$ Determined by Chiral HPLC analysis. ${ }^{c}$ Determined by ${ }^{1} \mathrm{H}$ NMR analysis of crude material. ${ }^{d}$ Performed on $9.6 \mathrm{mmol} \mathrm{scale.}{ }^{e}$ Isolated in 93:7 dr.

Further studies into the scope of the reaction were limited by the difficulty in the formation and isolation of certain ammonium salts. This was circumvented through the development of a one-pot protocol composed of in situ formation of the ammonium salt, followed by direct [2,3]-rearrangement under isothiourea catalysis (Table 3). As a direct comparison, treatment of $p$-nitrophenyl bromoacetate 7 with excess amine $31\left(\mathrm{R}^{1}=\right.$ phenyl) followed by rearrangement under standard conditions, gave both 14 and 19 in excellent yield, ee and dr with benzylamine and $\mathrm{NaOMe}$ as nucleophilic quenches. Pleasingly, this one-pot process allows the incorporation of 
Scheme 3: Mechanistic and Stereochemical Proposal

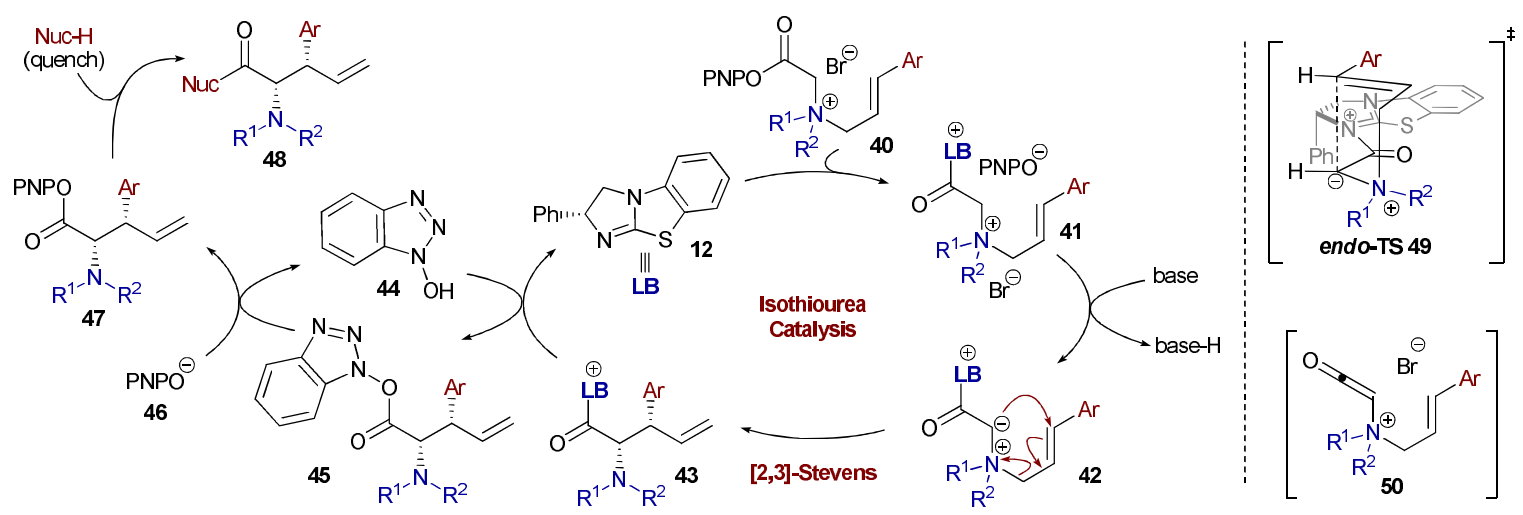

styryl, heteroaryl and alternative aryl functional groups (32-35), for which isolation of the corresponding ammonium salts proved difficult in our hands.

Table 3: In Situ Generated Ammonium Salts
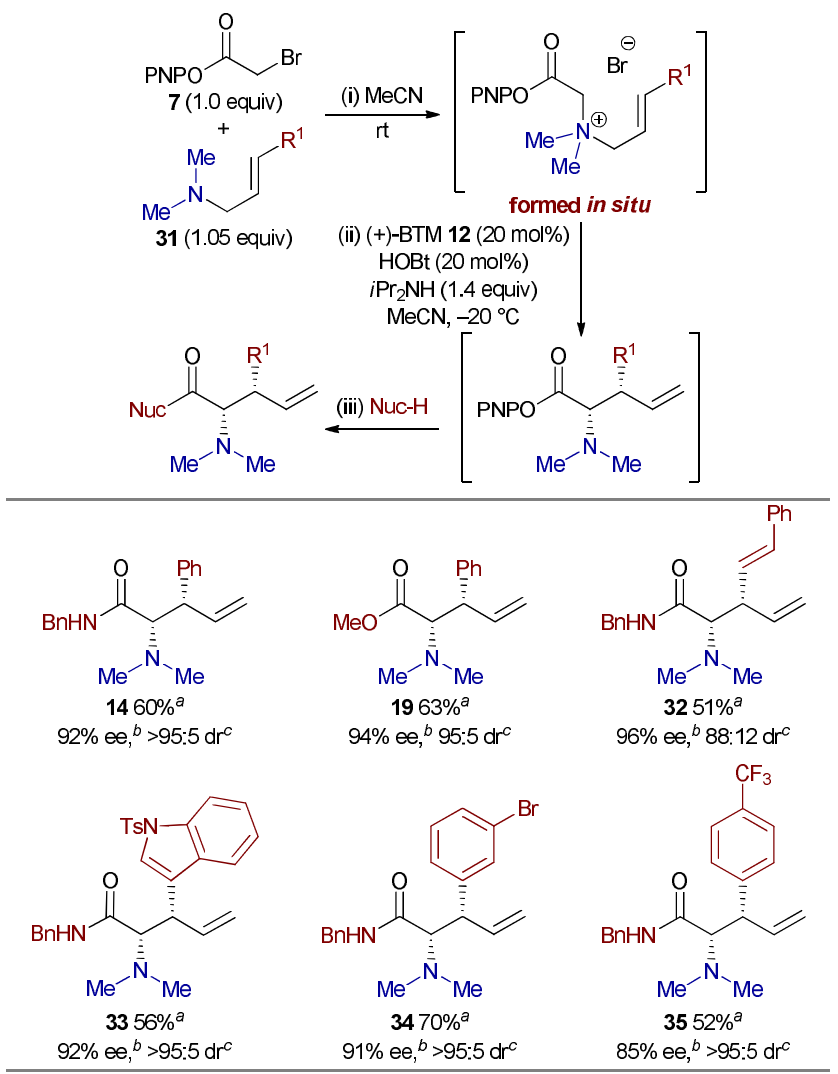

${ }^{a}$ Isolated yield after chromatographic purification of $>95: 5 \mathrm{dr}$; ${ }^{\mathrm{b}}$ Determined by Chiral HPLC analysis; ${ }^{c}$ Determined by ${ }^{1} \mathrm{H}$ NMR analysis of crude material.

Crossover studies with $\mathbf{3 6}$ and $\mathbf{3 7}$ (Scheme 2, eq 1) indicate that the allylic transfer process is intramolecular, consistent with the expected [2,3]-sigmatropic rearrangement. ${ }^{16}$ Further mechanistic investigations showed that epimerization or racemization is not observed upon retreatment of the major diastereoisomer to the reaction conditions. Probing of the substrate scope showed that reduced enantioselectivity (56\% ee) is observed with an $N$-allyl rather than a $N$-cinnamyl unit (39, Scheme 2,

eq 2), indicating that an aryl or vinyl unit is a structural requirement for high enantioselectivity in this process. ${ }^{17}$

Scheme 2: Mechanistically Significant Examples
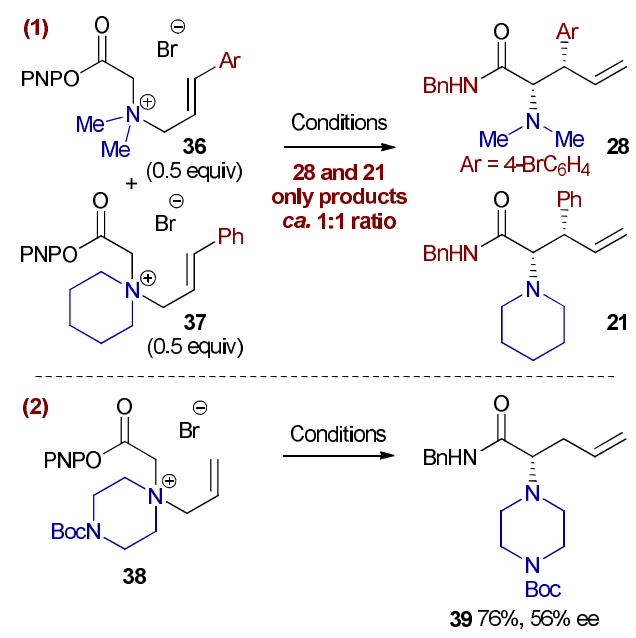

Conditions: (i) 12 (20 mol \%), HOBt (20 mol \%), $i \mathrm{Pr}_{2} \mathrm{NH}$ (1.4 equiv), $\mathrm{MeCN},-20{ }^{\circ} \mathrm{C}$; (ii) $\mathrm{BnNH}_{2}$ (5.0 equiv).

While a Brønsted base-catalyzed mechanism cannot be ruled out at present, the following mechanistic possibilities and catalytic cycle for this transformation are proposed (Scheme 3). Dicationic acyl ammonium ion $\mathbf{4 1}^{18}$ can be formed through direct $N$-acylation of (+)-BTM (12) with 40, with deprotonation of $\mathbf{4 1}$ with a suitable base forming ylide $\mathbf{4 2}$. Alternatively, $\mathbf{4 2}$ may arise from the addition of $\mathbf{1 2}$ to ketene $\mathbf{5 0}$, formed by formal elimination of $p$-nitrophenol from $\mathbf{4 0} .{ }^{19}[2,3]$-rearrangement of $\mathbf{4 2}$ gives acyl ammonium $\mathbf{4 3}$ that can either be intercepted by $p$-nitrophenoxide (46) or alternatively with HOBt (44) as a nucleophilic co-catalyst to give $\mathbf{4 7}$, in a second catalytic cycle as previously described by Rovis. ${ }^{15}$ The observed syn-diastereoselectivity ${ }^{20}$ may arise from the rearrangement occurring preferentially through an endo-type pre-transition state assembly 49. In this array, the carbonyl oxygen preferentially lies syn to the $\mathrm{S}$ atom within the isothiouronium ion, allowing a stabilizing $\mathrm{n}_{\mathrm{o}}$ to $\sigma^{*}{ }_{\mathrm{C}-\mathrm{S}}$ interaction ${ }^{21}$ or electrostatic stabilization. The stereodirecting $C(2)$-phenyl unit within 
BTM adopts a pseudoaxial position to minimize 1,2steric interactions. A $\pi$-cation interaction between the allylic $C(3)$-aryl or styryl substituent and the acyl ammonium ion, previously suggested in other asymmetric isothiourea catalyzed processes, ${ }^{21 \mathrm{~d}, 22}$ is proposed as key for high stereocontrol.

In summary, we have developed the first catalytic asymmetric [2,3]-rearrangement of allylic ammonium ylides. Isothiourea (+)-BTM 12 promotes the rearrangement of $p$-nitrophenyl ester ammonium salts, producing syn-configured $\alpha$-amino acid derivatives with excellent stereocontrol (up to >95:5 $d r$ and $>99 \% e e$ ). Further investigations into the mechanism of this process and applications of this reaction are currently being pursued in our laboratory.

\section{ASSOCIATED CONTENT}

Supporting Information: Complete experimental procedures including: X-ray structural data for 29, spectral and HPLC data for all novel compounds. This material is available free of charge via the Internet at http://pubs.acs.org.

\section{AUTHOR INFORMATION}

\section{Corresponding Author}

*ads10@st-andrews.ac.uk

Notes

The authors declare no competing financial interests.

\section{ACKNOWLEDGMENT}

We thank the Royal Society for a URF (ADS), the ERC under the European Union's Seventh Framework Programme (FP7/2007-2013, grant agreement No. 279850) (THW), and EPSRC grant No. EP/J018139/1 (DSBD) for funding. We also thank the EPSRC UK National Mass Spectrometry Service Centre at Swansea University.

\section{REFERENCES}

(1) (a) Stevens, T.S.; Creigton, E.M.; Gordon, A.B.; MacNicol, M. J. Chem. Soc., 1928, 3193-3197. (b) Millard, B. J.; Stevens, T. S.; J. Chem. Soc. 1963, 3397-3403. (c) Jemison, R. W.; Ollis, W. D.; J. Chem. Soc. D 1969, 294-295. (c) Marko, I. E. In Comprehensive Organic Synthesis; Trost, B. M., Fleming, I., Eds.; Pergamon Press: New York, 1991; Vol. 3, pp 913-974. (d) Bruckner, R. In Comprehensive Organic Synthesis; Trost, B. M., Fleming, I., Eds.; Pergamon Press: New York, 1991; Vol. 6, pp 873-908. (e) Nitrogen, Oxygen and Sulfur Ylide Chemistry, ed. J. S. Clark, Oxford University Press, Oxford, 2002.

(2) (a) Li, A. -H.; Dai, L. -X.; Aggarwal, V. K. Chem. Rev. 1997, 97, 2341-2372. (b) Arboré, A. P. A.; Cane-Honeysett, D. J.; Coldham, I.; Middleton, M. L. Synlett 2000, 236-238. (c) Sweeney, J. B. Chem. Soc. Rev. 2009, 38, 1027-1038. (d) Vanecko, J. A.; Wan, H.; West, F. G. Tetrahedron 2006, 62, 1043-1062.

(3) (a) Coldham, I.; Middleton, M. L.; Taylor, P. L. J. Chem. Soc., Perkin Trans. 1 1997, 2951-2952. (b) Coldham, I.; Middleton, M. L.; Taylor, P. L. J. Chem. Soc., Perkin Trans. 1 1998, 2817-2821. (c) Gawley, R. E.; Moon, K. Org. Lett. 2007, 9, 3093-3096.

(4) (a) Workman, J. A.; Garrido, N. P.; Sancon, J., Roberts, E.; Wessel, H. P.; Sweeney, J. B. J. Am. Chem. Soc. 2005, 127, 10661067. (b) Blid, J.; Panknin, O.; Somfai, P. J. J. Am. Chem. Soc. 2005, 127, 9352-9353.

(5) (a) Soheili, A; Tambar, U. K. J. Am. Chem. Soc. 2011, 133, 12956-12959. (b) Nash, A.; Soheili, A.; Tambar, U. K. Org. Lett. 2013, 15, 4770-4773. (c) Soheili, A; Tambar, U. K. Org. Lett. 2013, $15,5138-5141$.
(6) (a) Blid, J.; Brandt, P.; Somfai, P. J. Org. Chem. 2004, 69, 3043-3049. (b) Blid. J.; Panknin, O.; Tuzina, P.; Somfai, P. J. Org. Chem. 2007, 72, 1294-1300.

(7) MacMillan, D. W. C. Nature 2008, 455, 304-308

(8) Moyano, A.; El-Hamdouni, N.; Atlamsani, A. Chem. Eur. J. 2010, 16, 5260-5273.

(9) McNally, A.; Evans, B.; Gaunt, M. J. Angew. Chem. Int. Ed. 2006, 45, 2116-2119.

(10) (a) Yeh, P.-P.; Daniels, D. S. B.; Cordes, D. B.; Slawin, A. M. Z., Smith, A. D. Org. Lett. 2014, doi: . (b) Stark, D. G.; Morrill, L. C.; Yeh, P.-P.; Slawin, A. M. Z.; O'Riordan, T. J. C.; Smith, A. D. Angew. Chem. Int. Ed. 2013, 52, 11642-11646. (c) Morrill, L. C.; Douglas, J.; Lebl, T.; Slawin, A. M. Z.; Fox, D. J.; Smith, A. D. Chem. Sci. 2013, 4, 4146-4155. (d) Robinson, E. R. T.; Fallan, C.; Simal, C.; Slawin, A. M. Z.; Smith, A. D. Chem. Sci. 2013, 4, 2193-2200. (e) Simal, C.; Lebl, T.; Slawin, A. M. Z.; Smith, A. D. Angew. Chem. Int. Ed. 2012, 51, 3653-3657. (f) Belmessieri, D.; Morrill, L. C.; Simal, C.; Slawin, A. M. Z.; Smith, A. D. J. Am. Chem. Soc. 2011, 133, 2710-2714

(11) For a review, see: (a) Taylor, J. E.; Bull, S. D.; Williams, J. M. J. Chem. Soc. Rev. 2012, 41, 2109-2121. For seminal reports, see: (b) Birman, V. B.; Li, X. Org. Lett. 2006, 8, 1351-1354. (c) Birman, V. B.; Jiang, H.; Li, X.; Guo, L.; Uffman, E. W. J. Am. Chem. Soc. 2006, 128, 6536-6537. (d) Kobayashi, M.; Okamoto, S. Tetrahedron Lett. 2006, 47, 4347-4350.

(12) Chi and co-workers have used $p$-nitrophenyl esters in conjunction with NHCs as acyl azolium precursors, see: (a) Hao, L.; Du, Y.; Lv, H.; Chen, X.; Jiang, H.; Shao, Y.; Chi, Y. R. Org. Lett. 2012, 14, 2154-2157. (b) Hao, L.; Chen, S.; Xu, J.; Tiwari, B.; Fu, Z.; Li, T.; Lim, J.; Chi, Y. R. Org. Lett. 2013, 15, 4956-4959. (c) Xu, J.; Jin, Z.; Chi, Y. R. Org. Lett. 2013, 15, 5028-5031. (d) Chen, S.; Hao, L.; Zhang, Y.; Tiwari, B.; Chi, Y. R. Org. Lett. 2013, 15, 5822-5825.

(13) The $t$-butyl analogue of $\mathbf{1 3}$ was found to be inactive under the catalytic reaction conditions

(14) The rearranged $p$-nitrophenyl ester could be isolated, albeit in modest yield, see SI for details.

(15) Rovis has previously demonstrated the use of nucleophilic cocatalysts to facilitate the turnover of NHC catalysts, see: (a) Vora, $\mathrm{H}$. U.; Rovis, T. J. Am. Chem. Soc. 2007, 129, 13796-13797. (b) Wheeler, P.; Vora, H. U.; Rovis, T. Chem. Sci. 2013, 4, 1674-1679.

(16) See SI for a full optimization table and crossover experiments.

(17) Further investigation showed that the $(Z)$-cinnamyl isomer of 13 gave preferentially the syn-diastereoisomer but in reduced ee $(\mathrm{dr}$ $87: 13,64 \%$ ee), see SI for further information.

(18) Dicationic amidines are well characterized, see: Corr, M. J.; Gibson, K. F.; Kennedy, A. R.; Murphy J. A. J. Am. Chem. Soc. 2009, 131, 9174-9175.

(19) Ketenes can be generated from $p$-nitrophenyl esters under basic conditions, see: (a) Ketenes, $2^{\text {nd }} E d$. Tidwell, T. T. John Wiley \& Sons, Inc., Hoboken, 2006, pp 76-81. (b) Cho, B. R.; Kim, Y. K., Yoon, C. -O. M. J. Am. Chem. Soc. 1997, 119, 691-697. (c) Cho., B. R.; Jeong, H. C.; Seung, Y. J.; Pyun, S. Y. J. Org. Chem. 2002, 67, 5232-5238. For an example of an isolable cationic ketene, see: (d) Potts, K. T.; Murphy, P. M.; Kuehnling, W. R. J. Org. Chem. 1988, 53, 2889-2898

(20) Relative configuration of observed products determined by derivatization to ethyl ester SI XX (see SI) and comparison to literature data. Doyle, M. P.; Tamblyn, W. H.; Bagheri, V. J. Org. Chem. 1981, 46, 5094-5102. Absolute configuration determined by X-Ray analysis of 29, see SI for details. CCDC 981436 contains the supplementary crystallographic data for this paper. These data can be obtained free of charge from The Cambridge Crystallographic Data Centre via www.ccdc.cam.ac.uk/data_request/cif.

(21) (a) Minkin, V. I.; Minyaev, R. M. Chem. Rev. 2001, 101, 1247-1266. (b) Nagao, Y.; Hirata, T.; Goto, S.; Sano, S.; Kakehi, A. J. Am. Chem. Soc. 1998, 120, 3104-3110. (c) Brameld, K. A.; Kuhn, B.; Reuter, D. C.; Stahl, M. J. Chem. Inf. Model. 2008, 48, 1-24. (d) Liu, P.; Yang, X.; Birman, V. B.; Houk, K. N. Org. Lett. 2012, 14, 3288-3291.

(22) Yang, X.; Liu, P.; Houk, K. N.; Birman, V. B. Angew. Chem. Int. Ed. 2012, 51, 9638-9642. 
Authors are required to submit a graphic entry for the Table of Contents (TOC) that, in conjunction with the manuscript title, should give the reader a representative idea of one of the following: A key structure, reaction, equation, concept, or theorem, etc., that is discussed in the manuscript. Consult the journal's Instructions for Authors for TOC graphic specifications.

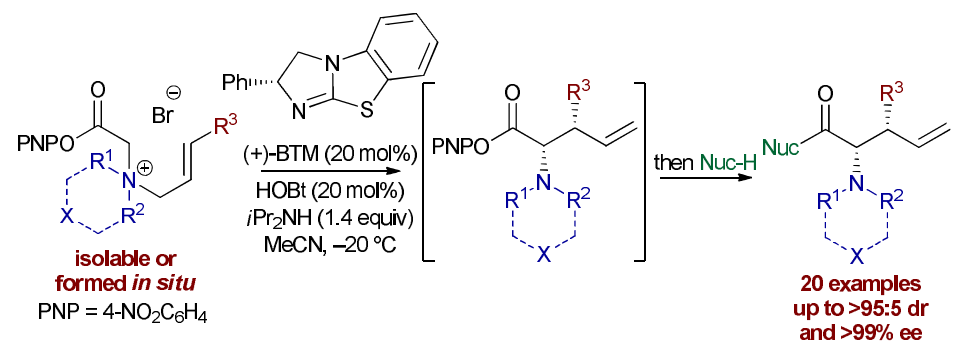

